\title{
Comment on: Out-of-hospital cardiac arrest: the prospect of E-CPR in the Maastricht region
}

\author{
M. T. Blom ${ }^{1}$ S. G. Beesems ${ }^{1} \cdot$ M. Hulleman ${ }^{1}$
}

Published online: 18 May 2016

(C) The Author(s) 2016. This article is available at SpringerLink with Open Access.

\section{Dear Editors,}

we read with great interest the study 'Out-of-hospital cardiac arrest: the prospect of E-CPR in the Maastricht region' by Sharma, Pijls and colleagues, as recently published by the Netherlands Heart Journal [1]. The survival rates after out-of-hospital cardiac arrest (OHCA) presented in this study are impressive. There is a great need for Dutch data on outcome after OHCA, and we applaud the efforts of the authors to collect and present these data.

However, the authors compare their results (survival after OHCA in patients who have been transported to hospital) with other studies that have different inclusion criteria (all OHCA patients, including those who die at the scene and are not transported to hospital [2, 3]). Evidently, survival rates in patients who were transported to hospital will be much higher. While the authors refer to an editorial recently published in this journal discussing this exact issue [4], they still make an incorrect comparison. Furthermore, the authors compare proportion of favourable neurological outcome in survivors (presumably defined as modified ranking score 0 ), with proportion of favourable neurological outcome (defined as cerebral performance category) of all OHCA patients in whom resuscitation was attempted, and state that the difference may be explained by presence of a shockable rhythm and early return of spontaneous circulation. This is surprising.

M. T. Blom

m.t.blom@amc.uva.nl

1 Academic Medical Center, University of Amsterdam, Amsterdam, the Netherlands
It would be very interesting to compare data on OHCA and outcome of resuscitation efforts in the Netherlands, using uniform inclusion and outcome definitions as recommended by the Utstein criteria [5]. This would provide valuable insight into factors influencing outcome after OHCA in the Netherlands.

Funding None.

Conflict of interest M.T. Blom, S.G. Beesems and M. Hulleman state that there are no conflicts of interest.

Open Access . This article is distributed under the terms of the Creative Commons Attribution 4.0 International License (http:// creativecommons.org/licenses/by/4.0/), which permits unrestricted use, distribution, and reproduction in any medium, provided you give appropriate credit to the original author(s) and the source, provide a link to the Creative Commons license, and indicate if changes were made.

\section{References}

1. Sharma AS, Pijls RW, Weerwind PW, et al. Out-of-hospital cardiac arrest: the prospect of E-CPR in the Maastricht region. Neth Heart J. 2016. doi:10.1007/s12471-015-0782-6.

2. Waalewijn RA, Vos R de, Koster RW. Out-of-hospital cardiac arrests in Amsterdam and its surrounding areas: results from the Amsterdam resuscitation study (ARREST) in 'Utstein' style. Resuscitation. 1998;38:157-167.

3. Blom MT, Beesems SG, Homma PC, et al. Improved survival after out-of-hospital cardiac arrest and use of automated external defibrillators. Circulation. 2014;130:1868-1875.

4. Koster RW. Apples in Amsterdam and oranges in Leiden. Neth Heart J. 2015;23:18-19.

5. Perkins GD, Jacobs IG, Nadkarni VM, et al. Cardiac arrest and cardiopulmonary resuscitation outcome reports: update of the Utstein resuscitation registry templates for out-of-hospital cardiac arrest: A statement for healthcare professionals from a task force of the international liaison committee on resuscitation; and the american heart association emergency cardiovascular care committee and the council on cardiopulmonary, critical care, Perioperative and resuscitation. Circulation. 2015;132:1286-1300. 